\title{
MĀORI LEADERS WELL-BEING: A SELF-DETERMINATION PERSPECTIVE
}

This research draw on interviews with 18 Māori leaders, over various leadership positions within business, community, political and marae organisations, to garner an understanding of how their leadership roles interact with their own well-being. Analysis of interviews revealed that cross cultural developments in Self Determination Theory (SDT) could be gained by incorporating Māori tikanga and values into a model of well-being for Māori leaders. Largely, the principles of tino rangatiratanga (autonomy and self determination), mana (respect and influence), whānau (extended family), whakapapa (shared history), and whanaungatanga (kin relations, consultation, engagement), were united into a model of leader well-being, Thus ensuring mātauranga Māori (Māori knowledge) informed Māori leader well-being, while also drawing on the burgeoning western research in the area of well-being, specifically Selfdetermination theory (SDT). Overall we find that similarities exist with SDT. However in contrast to SDT, the role of autonomy and competence, are developed in relationships, and thus 'others' underpins Māori leader's well-being. From this perspective, we present a view of the psychological and well-being resources which Māori leaders draw on to guide them through complex times. 


\section{Introduction}

Negativity, stress and burnout are antithetical to flourishing and vitality in leaders. Existing research, drawn mainly from Western researchers in America and Europe, suggests that leaders in all types of organisations are under increasing pressure due to the competitiveness, complexity of organisation systems, and change faced by leaders today. There is considerable evidence that this turbulent environment has taken its toll on leaders' psychological resilience and well-being (Melchior, Avshalom, Milne, Danese, Poulton, \& Moffitt, 2007; Andrea, Bultmann, van Amelsvoort \& Kant, 2009). Moreover, evidence suggests that by the very nature of the leadership role in influencing others, this negative reaction infiltrates through to others, including creating a negative impact on followers well-being (Bakker, Westman, \& Van Emmerik, 2009; Johnson, 2008; Sy, Côté, \& Saavedra, 2005). Thus, when leaders are stressed out, they are less able to support their followers, and this in turn negatively impacts on followers’ well-being (ten Brummelhuis, Haar \& Roche, 2014).

This situation is even more complex and ominous for Māori leaders. Māori leaders nurture growth in communities that have challenges over and above those of western organisations. While acknowledging other indigenous groups may share similar complications, in New Zealand, Māori represent one of the fastest growing ethnicity in New Zealand (Statistics New Zealand, 2013), however they also demonstrate a paucity of well-being, for example, being over represented in mental health outcomes including anxiety and depression (MaGPIe, 2005; Baxter, Kingi, Tapsell, Durie \& McGee, 2006; Wells, Browne, Scott, McGee, Baxter \& Kokaua, 2006), as well as being socially disadvantaged, due to high unemployment, and lower income in comparison to Europena/Pākehā ${ }^{1} \mathrm{New}$ Zealanders (Statistics New

\footnotetext{
${ }^{1}$ Please refer to the glossary - appendix one - for translations from Māori to English
} 
Zealand, 2013; Ministry of Business Innovation and Employment, 2013). Furthermore, Māori workforce participation is under-represented in high-skilled occupations (Te Puni Korkiri, 2009). While efforts have been made to remedy the disparity, such as settlement rights under The Treaty of Waitangi (legislation that acknowledges the rights of Māori and includes the protection of Māori interests, see Durie, 2006), the responsibility that Māori leaders have is unique in developing communities that are socially, psychologically and economically disadvantaged. While disparities continue to exist, Māori leaders are charged with the responsibility of drawing these communities together for positive change.

On one hand the challenges and pressure Māori leaders face are extraordinary, on the other hand, there are concerns regarding the lack of Māori leaders in New Zealand (Te Puni Korkiri, 2009; Wikitera, 2011; Te Rito, 2006). In acknowledging the complex and difficult time that Māori leaders work in, the aim of this paper is to examine the positive psychological resources that to equip these leaders to continue to lead in times of complexity and challenge. Scant research has examined the psychological resources Māori leaders draw upon to navigate through this complexity. However, examining the mental resources they call on to aid their own well-being is crucial in understanding and nurturing Māori leaders. This study enhances the understanding of Māori leaders' well-being in order to aid their ability to continue to positively influence and motivate the Māori community.

\section{What is the state of Māori leadership and well-being?}

Māori leaders work mostly within westernised societal structures. Politicians, business owners, iwi organisations and even marae leadership operate, or interact, with westernised social structures. Therefore, Māori leaders are not only likely to engage in leadership that supports westernised forms of leading, for example Authentic Leadership (Atewologun, 2013), Māori leaders are also expected to lead via the engagement in, and utilisation of, unique elements of 
Māori tikanga and values. Māori leaders place large emphasis on collectivism and egalitarian values (Katene, 2010). The idea of collectivism runs strongly through Māori culture to the point that Māori leaders often resist talking about their own achievements as personal credit is secondary to the importance of collective action (Diamond, 2003). Coupled with this however, is that within Māori organisations there is still formality and a level of respect for people's positions, known as mana (Schnurr, Marra, \& Holmes, 2007). Māori leadership however is not based on power and control over others, but rather focuses on being servants to the whānau, hapu, iwi, and wider social, organisational and political communities to which they belong (Wikitera, 2011).

The concept of mana and relationships are largely intertwined in Māori leadership literature (Te Rito, 2006). Leadership is described as relationships, that is the role of leadership is to build, nurture and sustain relationships (Te Rito, 2006; Wikitera, 2011; Spiller, Erakovic, Henare \& Pio, 2011). Māori leadership has been described as based on the notion of reciprocity (utu), mutual understandings, and leading through serving people (Wikitera, 2011). In today’s changing society Māori have identified that leadership is required more than ever. Therefore, Te Puna Kokiri produced a list of leadership guidelines that embodies the Māori tikanga within a leadership context. Such requirements could be viewed as unnerving and include major expectations of Māori leaders such as - a leader should serve the people, care for the people, listen to the peoples and speak on behalf of the people and from a traditional, contemporary, and futuristic perspective the primary obligation of a leader is to ensure the continuity and development of Māori society and culture, and a leader strives to enhance and strengthen the integrity of Māori society and culture.

Given the above complexities Māori leaders encounter, they require a wealth of psychological strength to engage in prescribed requirements of success. The challenges of leadership set by Te Puna Kokiri (2009), as well as leading via cultural values and western 
expectations, require a depth and strength of psychological ability that it is a formidable ask to take on a leadership role in this context. While research on Māori has predominantly been negative and discouraging (Smith, 1999), leading via engagement in Māori values has been found to garner relational, social, cultural and environmental well-being for Māori communities (Spiller et al., 2011). Thus while meeting these complex requirements taxes leaders' psychological resources, the engagement of Māori specific leadership seems advantageous to Māori.

In relation specifically to well-being, two streams of research have examined Māori well-being in general, and these have been particularly influential in Aotearoa/ New Zealand in the previous two decades. They are (1) Whare Tapa Wha [the four-sided house] (Durie, 2001) and (2) Te Wheke [the octopus] (Pere, 1995). The Whare Tapa Wha model has four walls, which represent the four dimensions of well-being hinengaro [psychological], whānau [family], wairua [spirit] and tinana [physical]. Psychological, family, spiritual and physical well-being are not viewed in isolation, but are interrelated and function in a synchronized manner to influence well-being. Similarly, Te Wheke employs an octopus metaphor to illustrate the interdependence of all the dimensions of well-being: the head represents the child/family and each tentacle represents an intertwined dimension that helps give nutrition to the whole. The eight tentacles represent, hinengaro [psychological], wairuatanga [spirituality], taha tinana [physical], whanaungatanga [extended family], mauri [life principle in people and objects], mana ake [unique identity], whatumanawa [emotional], and ha a koro ma a kui ma [inherited strengths]. Both the Whare Tapa Wha model and Te Wheke allude to psychological well-being for example both Whare Tapa Wha and Te Wheke examine (hinengaro) psychological well-being. While these models are holistic in terms of well-being for Māori, we aim to develop from these models a greater understanding of the area related to 
psychological well-being, as we contend this area of development is specifically required for supporting Māori leaders.

Thus, we suggest that is missing from the Māori leadership literature and the Māori well-being literature, is an understanding of Māori leaders’ psychological strength, and how this is nurtured and developed to equip them to continue to take on the challenges inherent and unique to Māori leadership. We add insight into Māori leader well-being, by developing and exploring the psychological well-being of leaders, who are required to harness their own strength, to aid others progress.

\section{Self-determination and Well-being.}

In the quest to better understand and enhance positive well-being researchers have drawn on the principals, research and theoretical developments in positive psychology (Wright \& Quick, 2009; Youssef \& Luthans, 2007; Little, Simmons, \& Nelson, 2007). While positive psychology expands and intensifies its theoretical and research base, the implications of psychological well-being in relation specific cultural contexts remains under examined (Csikszentmihalyi, 2009; ). Thus, acknowledging the limitations of positive psychology in cultural contexts such as in Aotearoa/New Zealand, in general advances in positive psychology have burgeoned. Increasing understanding of well-being has led to claims such as increased life expectancy, greater positive emotions, enhanced resiliency and better psychological health of leaders (Wright \& Quick, 2009; Csikszentmihalyi, 2009; Roche, Haar \& Luthans, 2014).

Two views of well-being exist in the western literature (Ryan \& Deci, 2001). Hedonic wellbeing, which is short term and externally motivated (ie. Wealth, image and fame) and

eudiamonic wellbeing (autonomous action, challenge and relationships). the view of wellbeing most aligned to existing Māori well-being models is that of eduaimonic well-being. 
Eudaimonic well-being is sort and gained via the engagement in meaningful endeavours and growth promoting experiences. Eduaimonic well-being stands in contrast to hedonic wellbeing that is gained via the pursuit of material wealth, or momentary states of 'feeling' happy (Ryan \& Deci, 2001).

Self-determination theory (SDT) is a eudaimonic theory of well-being that not only mirrors Māori values as further outlined below, but has become an increasingly employed framework for enhancing the theoretical understanding of well-being (Deci \& Ryan, 2000;). Specifically, SDT suggests that well-being is facilitated through engaging in autonomous action, seeking challenges, and connecting with others. Furthermore, within SDT, it is acknowledged that individuals can become passive and counter-productive (Deci \& Ryan, 2000). The assumption that humans are inherently active organisms does not imply that this tendency happens automatically. Indeed SDT maintains that the growth oriented nature of individuals requires that the fundamental "nutrients" of autonomy, competence and relatedness are a necessity, and must be met in order to aid well-being (Deci \& Ryan, 2000). Chirkov (2010: 2014) in supporting the three needs as universal and cross cultural in nature, also noted the importance of specific cultural values as central for indigenous peoples wellbeing. Consequently, we examine Māori leaders’ well-being, using both a cultural and selfdetermination lens.

\section{METHOD}

To establish a representative sample of Māori leaders across a wide variety of organisational types, maximum variation sampling was used as an overall strategy. Firstly, however, in order to identify leaders (given Māori reluctance to self-nominate) the researchers, utilizing a purposeful sampling method, engaged with their own networks of Iwi and community leaders. These leaders were asked to identify leaders they held in high esteem over a wide variety of 
sectors. These lists were compared by the researchers who identified common responses. The researchers then asked the leaders that were identified to also outline leaders they held in high esteem across the variety of organisational types. Again these lists were compared. Leaders were finally selected due to frequency of nomination, and to reflect diversity of leadership roles and variation of leadership position. This included leaders from political, business, community and marae leadership positions. Leaders identified were emailed and asked if they would take part in the study. In total 18 were interviewed, with 8 male and 10 female from various localities (including, Auckland, Wellington, Christchurch, Hamilton, Dunedin and a number of small regional locations) and business types.

\section{Interviews}

Data collection took place from March 2013 to December 2013. Interviews were individual face to face, semi structured interviews that allowed for multiple topics and concepts to be explored in detail (Smith \& Eatough, 2006). All participants were met at a time and place of their convenience throughout Aotearoa/ New Zealand (including meetings at maraes, electoral offices, business offices, and personal homes). Interviews lasted from 120 minutes to 240 minutes and were audio recorded and conducted by the researchers.

\section{Data Analysis}

All interviews were transcribed verbatim and analysed using interpretative phenomenological analytic (IPA) techniques. This method enables an exploration of the way participants make sense of their personal world and is useful for complex or novel topics (Smith \& Osborn, 2003). This is useful as it can capture the depth of an individual leaders' experience (Willig, 2001). IPA has been described as a way to explore personal and lived experiences while 
gaining and understanding of how participants have made sense of that experience (Smith, 2004).

Stage one began with a thematic analysis of transcripts, in order to confirm that wellbeing indicators were eudaimonic (c.f. hedonic) in nature. When this was established (for example - excerpt from story 17: ...it's possible for me to do that because I have no need to pursue money. I'm not saying we're wealthy I'm just not as driven by the need to make money) we undertook stage two analyses that focussed on the form of eudiamonic well-being in a Māori context.

We began this stage with a second detailed thematic analysis of each individual participants transcript as follows: first the transcript data was re-read and general eudaimonic related notes made. Secondly the notes were collated through these common themes into clusters. These were organised into major themes (i.e. relationships) and labelled as such. These more generalised themes were then cross referenced back to the data in all of the transcripts and it was at this stage connection with Māori tikanga were made (this is discussed further below but for example autonomy with tino rangatiratanga). Given the kaupapa Māori nature of the research (see Smith 1999 - research on Māori, by Māori and for Māori), regular discussion was taken place between the researchers to ensure that the cultural background was critical and clear in the analysis particularly as one researcher is Pākehā. Subsequently, NVivo was used to audit this process. Each major decision and stage of the study was discussed in detail by the authors and justified using previous literature.

\section{Results}

The themes that emerged from the Māori leaders interviews thus informed the research results. Overall, the analysis of Māori leaders interviews demonstrated that eudaimonic wellbeing was significant for their psychological wellbeing. While these themes were within the 
area of SDT the centrality of Māori tikanga was dominant. The themes were (1) autonomy (including tino rangatiratanga); (2) the development of their own and others competence including mana (respect and influence - self and others) and (3) relatedness (including whānau -extended family, whakapapa - shared history, whanaungatanga - kin relations, consultation, engagement). Each of these is discussed below.

\section{Autonomy, Competence and Relatedness a Māori Tikanga and SDT Perspective}

SDT suggests that well-being is gained by the experience of basic psychological needs for autonomy, competence and relatedness. Conditions that satisfy one's psychological needs facilitate well-being and growth, whereas conditions that impede need satisfaction thwart well-being and growth (Deci \& Ryan, 2000; Greguras \& Diefendorff, 2009). The satisfaction of these psychological needs is related to increased well-being (Sheldon, Ryan, \& Reis, 1996; Sheldon \& Elliot, 1999), vitality, (Reis, Sheldon, Gable, Roscoe, \& Ryan, 2000), positive affect (Sheldon, Elliot, Kim, \& Kasser, 2001), by time and gender (Chirkov, Ryan, Kim \& Kaplan, 2003) and these findings have been replicated across different cultures (e.g. Deci, Ryan, Gange, Leone, Usunov, Komasheva, 2001). As these results have been found across professional levels, sectors and cultures (e.g., Deci \& Ryan, 2000), SDT claims that satisfaction of these needs yield universal positive associations. The following extend SDT three needs by incorporating specific Māori values, and examining the role of these in understanding Māori leaders’ well-being.

\section{Autonomy}

Autonomy is defined as people's desire to experience ownership of their behaviour and to act with a sense of volition (Deci \& Ryan, 2000). Autonomy literally means 'self-governing' and 
implies, therefore, the experience of regulation by the self (Ryan, Huta \& Deci, 2008). Autonomy stands in contrast with heteronomy, which refers to the regulation of oneself by looking outside of the self, and compiling with these laws rather than others expectations. Therefore, the need for autonomy refers to the experience that behavior is owned and endorsed by the individual at the highest level of reflection, or psychological autonomy (Deci \& Ryan, 2000). Autonomy can be achieved through having the ability to make personal choices, and feeling like an initiator of one's own actions (Sheldon \& Filak, 2008; Deci \& Ryan, 2000; Sheldon \& Niemiec, 2006; Ryan et al., 2008). Autonomy is central in growth and development. The concept of autonomy in SDT research so far has been applied at the individual level. For Māori, who as outlined above, aspire to and are orientated towards the collective, autonomy is not only an individual concept, but the autonomy of others is also central. The need for 'collective' autonomy aligns well with the Māori concept of tino rangatiratanga, that espouses a pattern of (collective) volition and choice, in which governance and leadership is owned by Māori for Māori (Walker, 2004). Hence, reflecting the importance of relationships, that is in contrast to individual autonomy within SDT, both SDT and Māori well-being stand in contrast with heteronomy and compiling with others expectations. We found that Māori autonomy, operationalized collectively, aided leaders' well-being. Interviews focussed on developing the Māori way, irrespective of what others thought or others reactions or limitations placed on them. Further, this was supported in the interviews by the impact this Mãori way had on Māori communities. This was evident in the interviews of leaders.

Leader five (male), for example, is political leader who initiated kaupapa Māori schooling, including the use of only Te Reo in the school curriculum. In spite of repeated knock backs over many years this person took on and challenged the status quo. With every knock back the need for autonomy (collectively and via self-governing education), served as 
reinforcement for progress. Pleasure with the success was evident in the story where the leader indicated their satisfaction at 'getting around' the obstacles and enhancing Māori autonomy ...

They said...you can't have a school you don't have a building, a syllabus, a governance structure and you don't have a ... drinking fountain! A drinking fountain I said (incredulous laugh)... so we got everything done, well except the drinking fountain. When it came time for the Ministry to come by, they ticked everything off - then wanted to see the fountain....I got a hose and connected it to the next door property....here I said....here is the drinking tap....(laughing). We got it though. We got it....! ... and now look how Māori have grown, are growing ... at the number of Màori speaking Te Reo, the revival of Māori Tikanga...

Indeed, Māori language is thriving, with $21.3 \%$ of Māori being able to hold an everyday conversation in Te Reo Māori (Māori language) (Statistics New Zealand, 2013).

Another, female leader (leader seven), detailed similar experiences in terms of autonomy in terms of funding for a new project to aid Māori teenage mothers.

...But I knew teen parenting [in a specific regional area] was going to be an issue for Màori... So we knew we had to do it ... and we did it... in that year we lobbied for the teen parent unit to be built... and it got built ... there was no stopping me...but I was frightened the whole time... frightened of others who were more powerful than me...of not getting it done...of getting it done (laughing)!!

This story also highlights how autonomy is extended towards enhancing others autonomy...

In this teen unit....they have to do an expedition and these girls, because they have babies they had to take their babies on the expedition, the only time they weren't able to have their babies on the expedition was if they're out on the kayaks ... and they loved it... And these girls go on in life...they've got degrees, they're getting degrees, they're so highly motivated. Their kids now are motivated. They are true living successes. Seeing these girls, and now their kids, go and take on the world. That is what matters. Interviewee starts to cry.

Throughout interviews leaders spoke of how they worked for collective autonomy and enhanced autonomy of others, and the satisfaction this gave Māori leaders. Consequently, autonomy is fundamentally important for Māori leaders. The ability for Māori leaders to not 
only be self-governing in their behaviour, but developing others autonomy and selfdetermination, triggered satisfaction and consequently, enhanced well-being.

\section{Competence}

The concept of competence requires succeeding at optimally challenging tasks and attaining desired outcomes. White (1959) suggested that people engage in activities simply to experience efficacy and competence, and as such, competence refers to the need to feel a sense of capability and being able to master ones situation. For example, engaging in or undertaking activities in the workplace that enhance a feeling of growth and development is likely to enhance feelings of competence and therefore well-being. Given that Māori have unemployment rates in excess of the national average (14.1\% compared to 6.8\%, Ministry of Business Innovation and Employment, 2013), simply being in a leadership role may provide a strong sense of competence for Māori leaders, and enhance the well-being benefit.

While analysis (following below) showed that the leadership position did evoke competence and development, coupled with this was the importance for Māori leaders of building respect and mutual understanding (mana) in others as well. Thus competence for Māori leaders is enhanced when leadership competence is coupled with collective phenomena. Leader's who engage in competence, or challenging situations, engage in a way that builds relationships that aid reciprocity (utu) and respect of others (mana). In doing so a psychological benefit was attained. This is demonstrated in the following interviews.

Leader eight is a Māori woman who serves on many marae and community development boards throughout New Zealand/Aotearoa. Her interview included aspects of her own leadership competence (standing up and speaking out) as well as others competence development.

... It's like when you stand up in front of a whole lot of people, and you explain to them why ... you have to do it in your way as well as their way, so that they 
understand, and you put some passion into it, you know? ... a lot of the time it's a different world view and you just have to make them see it from your point of view... that is a challenge...

However, later in the interview this leader talks about a situation where she used the public forum as an opportunity to develop others competence.

... but it's also about allowing them to have their say and be acceptable to think that their say might be right, more right than yours! .... now that is scary standing up like that being all smart and then being small so others can stand tall (laughing)... that still scares me, looking stupid ... but I do it (be small) cause others need to come forward ... need to develop... that is what Māori do, make sure others also get to stand tall...

Leader seven has similar story

I got up in front of everyone. My knees were knocking and I was terrified ... but that wasn't going to stop me ...(laughing) actually I kind of liked it! ... but I carried on ... I knew some of those girls were watching me closely and I wanted them to feel like they could come forward with spark...

Leader nine (male) works within a Pākehā business organisation, but again reflects the collective competence building.

Always, I find that you have to always listen to a korero both ends and sometimes you have to recongise that others are taking risks too. And you have to be ready to support that. I mean you don't just accept someone's view just because you don't want to argue with them, or debate with them. Coz that doesn't make them worthy of what it is. But you always have to put yourself I guess in their situation to see, now if that was me what would I need ... stop looking higher than everybody else and just be with the people...let the others step up

Consequently, we found that the leadership position may in itself provide a sense of competence for Māori leaders, but this benefit is gained in relation to how these skills are used in a context of relatedness. Competence, as it relates to mastery of the self, may also for Māori be achieved through working with others on projects that challenge skills and behaviour, while also building the mana and relationships of others. This is support by Durie 
(2003) who asserted that meaningful work for Māori employees is likely to provide greater dignity and relationships.

This suggests that leaders may view their work as not only as meaningful and competence building, but this includes building others competence and mana. Over all, the interviews link towards competence and mastery in a leadership position, with competence development of others as particularly relevant for Māori leaders, and this appears to be beneficial for Māori leaders.

\section{Relatedness}

The need for relatedness is defined as the human striving for close and intimate relationships and the desire to achieve a sense of connection and belongingness and a sense of mutual respect, caring, and reliance on others (Ryan \& Deci, 2001; Baumeister \& Leary, 1995). Baumesiter and Leary (1995) suggested that human culture has at least partly adapted to enable people to satisfy the psychological for relatedness, and that belongingness is such a compelling need that human culture is significantly conditioned by the pressure to provide belongingness, and is a fundamental requirement for psychological well-being (Deci \& Ryan, 2000). This is supported more generally in positive well-being, for example, Diener and Seligman (2002) found that very happy people are characterized by substantially fulsome and satisfying interpersonal lives. For Māori, relatedness is a central cultural component in workplace wellbeing (Haar, Roche \& Taylor, 2012). The significant aspects of relatedness for Māori are (1) whakapapa and (2) whānau (3) whanaungatanga. Whakapapa includes being able to relate to people with whom a common ancestry is shared and relates to maintaining this sense of shared history and community, and includes the notion of valuing shared ancestry and how this community share a common home (marae) as the symbolic place/home for family and ancestors. 
Whānau relates to the extended, intergenerational family, and is a crucial concept for Māori because choices and decision-making processes can focus around the implications of these towards whānau. Consequently, these 'family bonds' are given priority over all other considerations in deciding what action to take, with whānau discussions focusing on benefits to the whole whānau rather than just some individuals. Some note that whānau is not a simple 'alternative' term for the nuclear family, as this fails to recognise the vastly different structure for Māori and importance of whānau, which may include intergenerational family structures, possible foster-relationships and other family and community connections and obligations (Edwards, McCreanor \& Moewaka-Barnes 2007; Metge, 1990). Whanaungatanga refers to inter-relationships and considers processes, the rituals of encounter both formal and informal (Salmond, 2013). This means situations where the commonalities and differences in relationships in the Māori world are both acknowledged and tested.

The interviews outline how interacting and working with whānau, facilitating whanaungatanga and acknowledging whakapapa, enable Māori leaders to appreciate a sense of belonging and connectedness.

Leader 12, a female, and chair of a post treaty organisation governance structure, as well as on many governance boards and roles, demonstrated the importance of whānau and whakapapa in her leadership journey.

It's quite old fashioned but my grandmother used to say to me that you don't put yourself forward for a role, that the people will do it for you and that to be really self critical about what your purpose is ... I was raised by my grandparents, and my grandmother lived with my husband and I and our children for 17 years. When she passed away we took her out to my marae... and at the tangi I offered my services to the whannau, just said if you need me to do anything I'm available and my thoughts were, at the time they were renovating the kitchen (at the marae), so I assumed that that's what they would ring me about ... But they rang me and asked me to stand for the board role for (Post Settlement Organisation)... So I said yes ... 
Leader 13 (male) is also an iwi settlement advisor and a community leader. He discussed the importance of whānau in his well-being.

.... That's managing the aspirations, the needs, the wants, the hopes of people that you represent ... This is about the people .... actually my family is my life I don't see any distinction between the hours that I've spent at work and the hours that I spend at home. This is all my life, I love what I do, I love my family, everything's my life and everything connects ... As soon as I stopped loving what I was doing I'd stop.

Leader 16 (female) works as a Māori business leader in a commercial organisation. She works at the executive level within this (Western/ Pākehā) organisation, although her role is in Māori development. She also discussed the role of whānau and whakapapa in her interview

The whole reason for my existence is to ensure that my family, my children and my mokopunas, inherit a world that is at least as great as the world that I was lucky to be born in, at least as great. ... So there's that, there's family. And also understanding that how I treat my old people has an influence on how my children and mokopunas will see the world too.

Leader 13, male and now a iwi settlement and community leader put it this way in terms of the connection between whānau, whakapapa and whanaungatanga and well-being

...you can't live in your home town without being involved in your own marae and the dynamics and operating the marae committee or hapu politics, and most of all your whânau dynamics and maintaining those... (In Wellington) I started realising that I needed support from some of my kaumatuas at home... probably 15-20 years ago, and it slowly built up to the point at which I knew, 10 years ago, that I was going to end up at home doing something, because without anyone saying it, that was the expectation of the people that were helping me ... be quite frank, I was quite scared of the prospect of going home. Because I'd never lived there, I'd never grown up there, and because I was known to all my whānau I was also known to not be someone who had lived there and grown up there, not born and bred. Which is for people who have stayed home all their lives and kept the home fires burning, is a very very proud badge for them to wear and I didn't ever see me as qualifying in that role, serving at home ... now I would never go back to Wellington, to the life there...

All the interviews connected whānau and whakapapa with well-being. The connection to wider family and support networks, and working for these networks, fuelled leaders' well- 
being. The sense of belonging to, and the sense of giving back to whānau, created a meaningful connection and experience for these leaders.

\section{Discussion}

Eudaimonic well-being is gained via engagement in worthy activities - ones that aid growth and development, and this stands in contrast to hedonic well-being that is gained via purely pleasure seeking activities and the pursuit of wealth. Māori leader's interviews support the notion of well-being being sought in meaningful and growth promoting endeavours. Drawing from SDT and the three 'nutriments' of eudaimonic well-being, interviews from Māori leaders highlighted that well-being is gained in autonomy and competence, but in contrast to SDT, this was specifically in relation to developing others autonomy and competence. In relation to need for relatedness, this was central for Māori leaders in terms of the role of whānau and whakapapa towards well-being. Thus, for Māori leaders, each of the three needs is a required 'nutriment' for well-being. However in contrast to SDT theory, these are not gained separately, but each of the three needs is interconnected, with the mechanism of that connectedness being relatedness.

As outlined earlier on, 'relatedness' is also key theme in how Māori leaders 'lead'. Māori leadership is viewed as being based on influencing relationships and growing relationships. Interestingly, we find this theme also emerges in understanding Māori leaders’ well-being. Thus for Māori leaders relationships are both a leadership practice, but they also garner well-being outcomes for them. In nurturing leaders, this finding could be highlighted. Suggesting that in development programs for leaders, not only the role of relationships in leadership matter, but emphasising the role of this in their own well-being will be beneficial for their survival in the leadership labyrinth they operate in. 
Adapting SDT to incorporate Māori tikanga provides an overarching lens for which Māori lead well-being research and practice can grow. Csikszentmihalyi (2009) referred to indigenous societies who had richer lives by having different forms of recognition and rewards that were not reduced to a monetary metric, but instead a focus on community, relationships, customs and traditions. The present study suggests this might be applicable for Māori leaders well-being and towards their indigenous cultural traditions especially in the leadership setting.

While we find the three needs in relation to hinengaro (psychological well-being) are important, future research may delve further into existing models of Māori well-being and examine how this also aids leader well-being. For example what role does tinana [physical], and wairua [spirit], play in equipping Māori leaders to take on challenges? We encourage future research to develop and investigate this. Future research on other indigenous leaders' well-being would also benefit. How is this model of well-being similar and/or different in understanding and nurturing aboriginal/torre islander leader's? for example.

In summary, the present study finds that autonomy development of self and others, competence building of self and others, and valuing and interacting with whānau all act as a basis for the psychological well-being of Māori leaders. Thus, while drawing from SDT and satisfaction of an individual's psychological needs (Ryan et al., 2008), this perspective allowed for a greater understanding of how indigenous leaders well-being can be potentially enhanced through cultural factors, while meeting psychological needs, and overall this was supported.

\section{Conclusion}

Csikszentmihalyi (2009) suggested assessment and understanding of the social fabric, norms and values that govern the way we live out our lives is a worthy pursuit for positive psychology. As such, and answering those calls, we found that based on an understanding of 
positive psychology but weaved, understood and developed within indigenous culture, we can gain an understanding of Māori leaders' positive psychological resources that aid in wellbeing. While future studies are needed to examine the cross-cultural findings here, such as relevance to other indigenous people (Csikszentmihalyi, 2009), overall this study on Māori leaders well-being demonstrated similarities with SDT, but differences, as expected, were apparent.

Within Aoteroa/New Zealand there has been a strong growth in Māori culture. Such a renaissance has lead Māori researchers to reiterate the importance of understanding Te Aro Māori (the Māori world), and recognising and valuing Māori Tikanga (customs) and traditions (Harris, 2007; Walker, 2006) along with calls for greater Māori leadership to come forward. This study has a potential useful addition to understanding Māori leaders' psychological resources and thus makes a contribution to nurturing their psychological wellbeing. Moreover, this study provides initial support for the value and importance of Māori tikanga combined with positive psychology. In understanding this we not only aid in combating the stress leader's encounter as they engage in the demanding situations associated with Māori leadership, but we also highlight the need to nurture and support leaders' as they continue to respond to the pressures coming from the present and future environment.

As Csikszentmihalyi notes in terms of positive psychology "The next big challenge for this new field is to help improving the social and cultural conditions in which people live" (2009, p. 203). The present study provides an initial direction for researchers on indigenous well-being and should provide encouragement for researchers seeking to applying cultural values and beliefs towards understanding the well-being of indigenous peoples. 


\section{REFERENCES}

Atewologun, D. (2013). Developing authentic leadership as a racial minority in Ladkin, D., \& Spiller, C. (Eds.). Authentic Leadership: Clashes, Convergences and Coalescences. Edward Elgar Publishing. 252 -255.

Andrea, H., Bultmann, U., van Amelsvoort, L. G., \& Kant, Y. (2009). The incidence of anxiety and depression among employees - the role of psychosocial work characteristics. Depression \& Anxiety, 26(11), 1040-1048.

Baumeister, R.F. \& Leary, M. (1995). The need to belong: Desire for interpersonal attachments as a fundamental human motivation. Psychologicla Bulletin, 117(3), 497-529.

Bakker, A. B., Westman, M., \& Van Emmerik, I, J. H. (2009). Advancements in crossover theory. Journal of Managerial Psychology, 24, 206-219.

Baxter, J., Kingi, T. K., Tapsell, R., Durie, M. \& McGee, M. A. (2006). Prevalence of mental disorders among Māori in Te Rau Hinengaro: The New Zealand Mental Health Survey. Australian and New Zealand Journal of Psychiatry, 40(10), 914-923.

Cram, F., Smith, L., \& Johnstone, W. (2003). Mapping the themes of Māori talk about health. New Zealand Medical Journal, 116(1170), 1 e7.

Chirkov, V. (2014). The Universality of Psychological Autonomy Across Cultures: Arguments from Developmental and Social Psychology. In Human Motivation and Interpersonal Relationships (pp. 27-51). Springer Netherlands.

Chirkov, V. (2010). Dialectical Relationships among Human Autonomy, the Brain, and Culture. In Chirkov, V., Ryan, R., \& Sheldon, K. (Eds). Human Autonomy in Cultural Contexts: Perspectives on the Psychology of Agency, Freedom, and People's Well-Being. Springer. 
Chirkov, V., Ryan, R. M., Kim, Y., \& Kaplan, U. (2003). Differentiating autonomy from individualism and independence: A self-determination theory perspective on internalization of cultural orientations and well-being. Journal of Personality and Social Psychology, 84(1), 97-110

Csikszentmihalyi, M. (2009). The promise of positive psychology. Psychological Topics, 18 (2), 203-211.

Deci, E. L., \& Ryan, R. M. (2000). The “what”' and the "why” of goal pursuits: Human needs and the self-determination of behavior. Psychological Inquiry, 11, 227268.

Deci, E. L., \& Ryan, R. M. (2008). Facilitating optimal motivation and psychological wellbeing across life’s domains. Canadian Psychology, 49, 14-23.

Deci, E. L., Ryan, R. M., Gange, M., Leone, D. R., Usunov, J., \& Komasheva, B. P. (2001). Need satisfaction, motivation, and well-being in the work organizations of a former eastern bloc country: a cross-cultural study of Self-Determination. Personality and Social Psychology Bulletin, 2(8), 930-942.

Diamond, P. (2003). A fire in your belly: Mãori leaders speak. Huia Publishers.

Diener, E., \& Seligman, M. E. P. (2002). Very happy people. Psychological Sciences. 13(1) $181-184$.

Durie, M. (2001). Mauri Ora: The dynamics of Māori health . Auckland: Oxford University Press.

Durie, M. (2003). Nga Kahui Pou: Launching Māori Futures. Wellington, New Zealand: Huia Publishers.

Durie, M. (2006). Te Mana, Te Kawanatanga: The Politics of Māori Self-Determination. Wellington, New Zealand: Oxford University Press. 
Edwards, S., McCreanor, T., Moewaka-Barnes, H., \& Whariki, T. R. (2007). Māori family culture: A context of youth development in Counties/Manukau. New Zealand Journal of Social Sciences Online, 2, 1-15.

Elisabeth Wells, J., Oakley Browne, M. A., Scott, K. M., McGee, M. A., Baxter, J. \& Kokaua, J. (2006). Te Rau Hinengaro: The New Zealand Mental Health Survey: Overview of methods and findings. Australian and New Zealand Journal of Psychiatry, 40(10), 835-844.

Greguras, G. J. \& Diefendorff, J. M. (2009). Different fits satisfy different needs: Linking person-environment fit to employee commitment and performance using selfdetermination theory. Journal of Applied Psychology, 94(2), 465-477.

Haar, J. M., Roche, M. A. \& Taylor, D. (2012). Work-family conflict and turnover intentions of indigenous employees: the importance of whanau/family for Maori. The International Journal of Human Resource Management. 23(12), 2546-2560.

Harris, N. T. A. (2007). Work life balance: A Māori Women's perspective. Auckland: Auckland University of Technology.

House, R. J. (2004). Culture, leadership and organizations: The GLOBE study of 62 societies. Sage, USA.

Johnson, S. K. (2008). I second that emotion: Effects of emotional contagion and affect at work on leader and follower outcomes. The Leadership Quarterly, 19(2), 1-19.

Katene, S. (2010). Modelling Māori leadership: What makes for good leadership?. MAI Review, 2.

Kasser, T. \& Ryan, R. M. (1996). Further examining the American dream: Differential correlates of intrinsic and extrinsic goals. Personality and Social Psychology Bulletin, 22, 280-287. 
Kasser, M., Ryan, R. M., Couchman, C. E., \& Sheldon, K. M. (2004). Materialistic values: Their causes and consequences. In T. Kasser \& A. D. Kanfer (Eds.), Psychology and consumer cultures: The struggle for a good life in a materialistic world (pp. 11-28). Washington, DC: American Psychological Association.

Little, L. M., Simmons, B. L., \& Nelson, D. L. (2007). Health among leaders: Positive and negative affect, engagement and burnout, forgiveness and revenge, Journal of Management Studies, 44(2), 243-260.

MaGPIe. (2005). Mental disorders among Māori attending their general practitioner. Australian and New Zealand Journal of Psychiatry, 39(5), 401-406.

Melchior, M., Avshalom, C., Milne, B. J., Danese, A., Poulton, R., \& Moffitt, T. E. (2007). Work stress precipitates depression and anxiety in young, working women and men. Occupational Environment Medicine, 37(8), 1119-1129.

Metge, J. (1990). Te Rito o te Harakeke: Conceptions of the Whanau. Journal of the Polynesian Society, 99(1), 55-92.

Ministry of Business Innovation and Employment. (2013). Māori Labour Market Factsheet March 2013. Wellington: Statistics New Zealand.

Pere, R. (1995).Te Wheke: a celebration of infinite wisdom (2nd ed.).Gisborne, NZ: Ao Ako.

Reis, H. T., Sheldon, K. M., Gable, S. L., Roscoe, J., \& Ryan, R. M. (2000). Daily well being: The role of autonomy, competence, and relatedness. Personality and Social Psychology Bulletin, 26, 419-435.

Roche, M.A., Haar, J. \& Luthans, F. (2014). The role of mindfulness and psychological capital on the well-being of leaders. Journal of Occupational and Health Psychology. 19(4), 476-783. 
Ryan, R. M., \& Deci, E . L. (2001). On happiness and human potentials: A review of research on hedonic and eudaimonic well-being. Annual Review of Psychology. 52(1), 141166.

Ryan, R. M., Huta, V. Deci, E. L. (2008). Living well: a Self Determination theory perspective on eduaimonia. Journal of Happiness Studies, 9, 139-170.

Salmond, A. (2013). Anthropology, ontology and the Māori world. Up Close And Personal: On Peripheral Perspectives and the Production of Anthropological Knowledge, 25, 58.

Schnurr, S., Marra, M., \& Holmes, J. (2007). Being (im) polite in New Zealand workplaces: Māori and Pākehā leaders. Journal of Pragmatics, 39(4), 712-729.

Sheldon, K. M., Elliot, A. J. (1999). Goal striving, need satisfaction, and longitudinal wellbeing: The self-concordance model. Journal of Personality and Social Psychology, 76(3), $482-497$.

Sheldon, K. M., Elliot, A. J., Kim, Y., \& Kasser, T. (2001). What Is Satisfying About Satisfying Events? Testing 10 Candidate Psychological Needs. Journal of Personality and Social Psychology, 80(2), 325-339.

Sheldon, K., \& Filak, V. (2008). Manipulating autonomy, competence, and relatedness support in a game-learning context: new evidence that all three needs matter. British Journal of Social Psychology, 47, 267-283.

Sheldon, K., \& Niemiec, C. (2006). It's not just the amount that counts. Balance need satisfaction also affects well-being. Journal of Personality and Social Psychology, 91(2), 231-341.

Sheldon, K. M., Ryan, R., Reiss, H.T. (1996). What makes for a good day? Competence and autonomy in the day of a person. Personality and Social Psychology Bulletin. 22(12), $1280-1288$. 
Sheldon, K. M., Elliot, A. J., Ryan, R. M., Chirkov, V., Kim, Y., Wu, C., Demir, M., \& Sun, Z. (2004). Self-concordance and subjective well-being in four cultures. Journal of Cross-Cultural Psychology, 35(2), 209-223.

Smith, L. T. (1999). Decolonizing Methodologies: Research and Indigenous People. London: Zed Books Ltd.

Smith, J. A., \& Eatough, V. (2006). Interpretative phenomenological analysis. In G. M. Breakwell, S. Hammond, C. Fife-Shaw, \& J. A. Smith (Eds.), Research methods in psychology (3rd ed.). (pp. 322e341) London: SAGE Publications.

Smith, J. A. (2004). Reflecting on the development of interpretative phenomenological analysis and its contribution to qualitative research in psychology. Qualitative research in psychology, 1(1), 39-54.

Smith, J. A., \& Osborn, M. (2003). Interpretive phenomenological analysis. In J. A. Smith (Ed.), Qualitative psychology: A practical guide to research methods (pp. 52e80). London: Sage Publications.

Spiller, C., Erakovic, L., Henare, M., \& Pio, E. (2011). Relational well-being and wealth: Māori businesses and an ethic of care. Journal of Business Ethics,98(1), 153-169.

Statistics New Zealand. (2013). QuickStats about Maori. Wellington: Statistics New Zealand. Sy, T., Côté, S., \& Saavedra, R., (2005). The contagious leader: Impact of the leader's mood on the mood of group members, group affective tone, and group processes. Journal of Applied Psychology, 90(2), 295-305.

ten Brummelhuis, L., Haar, J. M., \& Roche, M. A. (2014). Does family life help to be a better leader? A closer look at crossover processes from leaders to followers. Personnel Psychology. DOI: 10.1111/peps.12057.

Te Rito, P. (2006). Leadership in Māori, Europena/Pākehācultures and in the world of sport. Mai Review, 1, 1-19. 
Te Puni Korkiri. (2009). Moni Utunga Māori: Māori Earnings. Wellington: Te Puni Korkiri.

Walker, R. (2004). Ka Whawhai Tonu Matou: Struggle without End (Revised Edition).

Auckland: Penguin Books.

Walker, T. (2006). Whanau is Whanau: Blue Skies Report. Wellington: Families Commission.

White, R. W. (1959). Motivation reconsidered. The concept of competence. Psychological Review, 66(5), 297-333.

Willig, C. (2001). Introducing qualitative research in psychology: Adventures in theory and method. Buckingham: Open University Press.

Wikitera, K. A. (2011). Travelling, Navigating and Negotiating Māori Leadership Challenges in the 21st Century. MAI Review,2, 2-4.

Wright, T. A. \& Quick, J. C. (2009). The emerging positive agenda in organizations: Greater than a trickle, but not yet a deluge. Journal of Organizational Behavior, 30, 147-159.

Youssef, C. M., \& Luthans, F. (2007). Positive organizational behaviour in the workplace. Journal of Management, 33(5), 774-803. 